\title{
MANNHEIM PERITONITIS INDEX (MPI) SCORE AS A PREDICTOR OF OUTCOME IN PATIENTS WITH SECONDARY PERITONITIS
}

\author{
Pravin Joshi ${ }^{1,}$ Rajesh Poudel $^{2,}$ Kailash Chandra ${ }^{2}$
}

\section{ABSTRACT}

\section{INTRODUCTION:}

Secondary bacterial peritonitis from hollow viscous perforation is one of the common surgical emergencies and carries higher mortality. Several scoring systems are applied to predict the outcome of patients with perforation peritonitis. Mannheim Peritonitis Index (MPI) is one among many. Our aim of the study is to evaluate Mannheim peritonitis Index for predicting the outcome in patient with secondary bacterial peritonitis.

\section{MATERIALS AND METHODS:}

A retrospective study was conducted in the Department of General Surgery, Universal College of Medical Sciences, Bhairahawa from February 2012 to July 2013. All patients clinically diagnosed as peritonitis and who underwent laparotomy were included in the study. MPI score of all the study patients were calculated and categorized into three groups depending upon the score; less than 15, 15-25 and more than 25. Mortality of patients from each group was calculated and predictive value of each factor was determined.

\section{RESULTS:}

Total 60 patients were included in the study. Forty-four were male and sixteen were female. There were total five mortalities. All were of above 50 years age group. Patients beyond 50 years of age had a significantly higher $(p=.005)$ probability of dying in the early post-operative period. MPI score more than 15 was not statistically significant $(p=.06)$, patients with MPI more than 25 had more probability of dying, hazard ratio (HR 3.4 with $95 \% \mathrm{CI}$ ).

\section{KEYWORDS:}

Mannheim, Mortality, Peritonitis, Predictors

1. Consultant Surgeon, Human Organ Transplantation Centre, Bhaktapur, Nepal

2. Department of Surgery, Universal College of Medical Sciences, Bhairawha, Nepal

\author{
For Correspondance: \\ Dr. Rajesh Poudel \\ Assistant Professor \\ Department of Surgery \\ UCMS, Bhairawha, Nepal \\ rajeshpoudel@yahoo.com
}




\section{INTRODUCTION}

Surgical treatment of peritonitis was introduced by Kirschner in 1926. Several scoring systems are applied to predict the outcome of patients with perforation peritonitis. Acute Physiology and Chronic Health Evaluation System (APACHE) scores, Simplified Acute Physiology Score (SAPS), Sepsis Score, Multiple Organ Failure Score and Mannheim Peritonitis Index (MPI) $)^{1,2}$ are a few examples.

Peritonitis is one of the commonest surgical emergencies and carries high mortality ${ }^{3}$. Some pre-operative scoring systems provide approximate estimates of mortality risk but none has been shown to be adequate. Various authors have reported APACHE to be a better system for prognostication of the outcome of patients with peritonitis; while others concluded that MPI provides a more reliable and simple means of risk evaluation ${ }^{4,5}$. The MPI as proposed by Wacha ${ }^{6}$ was an analysis of 17 possible risk factors, of which 8 were of prognostic significance (Table 1). Patients are grouped into three categories depending upon the score; less than 15,15 to 25 and more than 25. According to MPI, higher the score worse is the outcome.

Table 1: Mannheim Peritonitis Index

\begin{tabular}{|lc|}
\hline Risk Factor & Points \\
\hline Age $>50$ years & 5 \\
Female sex & 5 \\
Organ failure & 7 \\
Malignancy & 4 \\
Preoperative duration of & \\
Peritonitis $>24 \mathrm{~h}$ & 4 \\
Origin of sepsis not colonic & 4 \\
Diffuse generalized peritonitis & 6 \\
Exudate & \\
Clear & 0 \\
Cloudy, Purulent & 6 \\
Fecal & 12 \\
\hline Definitions of Organ Failure \\
Kidney Creatinine level $>177 \mu \mathrm{mol} / \mathrm{L}$ \\
Urea level $>167$ mmol/L \\
Oliguria $<20 \mathrm{ml} / \mathrm{h}$ \\
Lung PO2 $<50 \mathrm{mmHg}$ \\
PCO2 $>50$ mmHg \\
Shock Hypodynamic or Hyperdynamic \\
Intestinal obstruction Paralysis $>24 \mathrm{~h}$ or \\
complete mechanical obstruction \\
\hline
\end{tabular}

\section{METHOD}

A retrospective study was conducted in the Department of General Surgery, Universal College of Medical Sciences, from February 2012 to July 2013. All patients clinically diagnosed as peritonitis and who underwent laparotomy, included in the study. Traumatic peritonitis associated with other injuries and relaparotomy for tertiary peritonitis were excluded.

MPI score of all the study patients were calculated and categorized into three groups depending upon the score; less than 15, 15-25 and more than 25. Mortality of patients from each group was calculated and predictive value of each factor was determined.

\section{RESULTS}

Total of 60 patients were included in the study. Forty-four were male and sixteen were female. The etiologies of peritonitis were also variable (Figure 1).

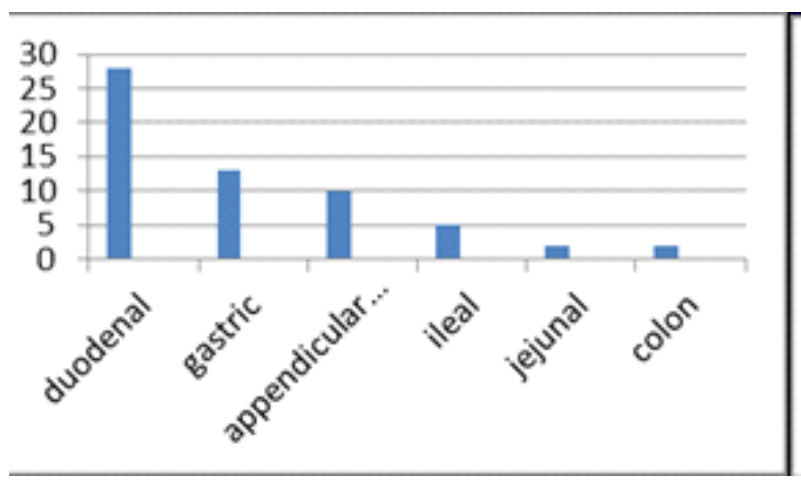

Figure 1: Causes of perforation and peritonitis.

There were total five mortalities. All were of above 50 years age group. Patients beyond 50 years of age had a significantly higher $(\mathrm{p}=.005)$ probability of dying in the early postoperative period (Figure 2).

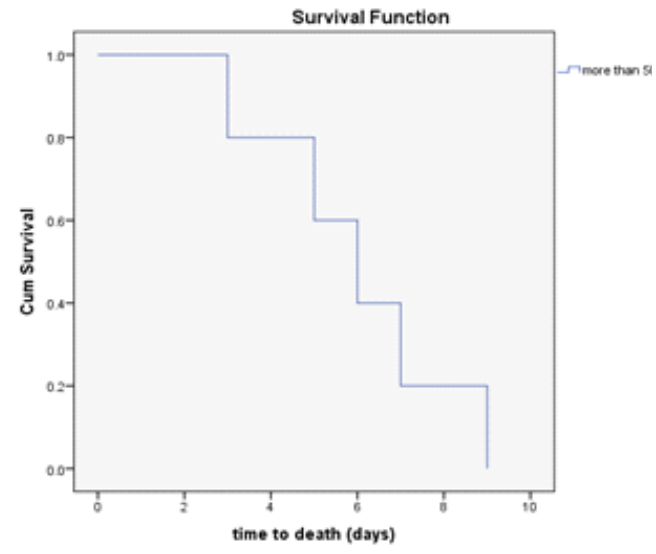

Figure 2: Kaplan-Meier curve survival curve. 
Among all 16 female patients, single mortality was recorded. So, female sex is not found as a risk factor in our study. Three patients had signs of organ failure and two patients among them died after surgery. However, no patient in the study group was diagnosed to have malignancy. Twenty-two patients presented with symptoms for less than 24 hours and three mortalities recorded in this subset of patients. Similarly, thirty-eight had symptoms for more than 24 hours and two patients died in this group, outcome was not significantly associated with duration. Among eight patients with localized peritonitis, no mortality was recorded. There were three patients with colonic perforation and one patient died, statistically not significant. All five patients among the mortality group were above 50 years of age. Average age of the patients who died was 65 and average age of the patients who survived was 43 . So, age above 60 years was associated with poor outcome. Older patients are more likely to get higher MPI score and mortality

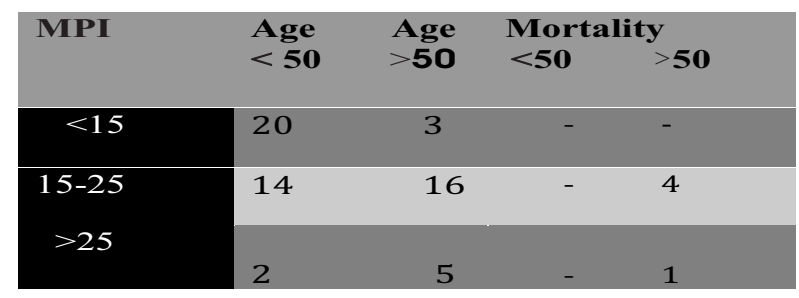

Figure 3: Correlation of Age, MPI and outcome

Although MPI score more than 15 was not statistically significant $(\mathrm{p}=.06)$, patients with MPI more than 25 had more probability of dying, hazard ratio (HR 3.4 with 95\% CI). There were 4 patient recorded as having feculent contamination, both had colonic perforation, and one patient died. Two patients had clear fluid and remaining all had purulent collection.

\section{DISCUSSION}

Generalized peritonitis, mostly secondary, is still a significant surgical problem. ${ }^{7,8}$ But data are relatively scarce for this very common problem. In most cases patients present to hospital in late stage with established peritonitis and sepsis. This contributes significant burden to our medical services and loss to society, as many of the affected patients are young individuals. It is necessary to recognize patients at higher risk preoperatively. This becomes even more important in our setup, as the intensive care facilities are limited and overwhelmed by the number of patients. Age, sex, site of perforation, preoperative shock, hypoglycemia, renal dysfunction, duration, and delay in surgical treatment, have been reported as the determinants of mortality in patients with perforation peritonitis. Similarly hyperlactatemia, lactic acidosis, increased Tumor necrosis factor, procalcitonin levels, and intramucosal gastric $\mathrm{pH}$, have been considered as ${ }_{15}$ indirect determinants of sepsis and patients' outcome ${ }^{11,12,13,14 \text {, }}$

Studies had shown that the results of elective surgery in elderly patients seem largely favorable, while those of emergency surgery are not ${ }^{6}$. Cohen ${ }^{17}$ and Seo et al., ${ }^{18}$ have reported a high risk of mortality in patients over 60 . In our study, age above 60 years is found to be a significant determinant of outcome.

Jhobta 19 and Afridi et al., ${ }^{20}$ have stressed that delayed presentation to the hospital accounts for significant mortality. Kocer et al., ${ }^{21}$ reported that patients who were admitted after 24 hours had a 3.4 times higher mobidity risk than patients admitted before 24 hours. Svanes et al., ${ }^{22}$ have reported that a delay of more than 24 hours increases lethality from sevenfold to eight-fold, complication rate to three-fold, and length of hospital stay to two-fold, compared to a delay of six hours or less. In our study delay of 24 hours was not significantly associated with poor outcome. One reason for this may be that, being a retrospective study the physician who first evaluated the patient might not be very scrupulous about the duration. Since, most of our patients present very late, 24 hours may be too short to reflect any difference, so longer duration (?24 hours) can be used.

Several scoring indices have been compiled to predict the prognosis of patients with sepsis. The Boey score encompasses only three factors - major medical illness, preoperative shock, and long standing perforation $(\geq 24$ hours). The mortality rate increases progressively with an increasing number of risk factors: $0,10,45.5$, and $100 \%$ in patients with none, one, two, and all three risk factors, respectively ${ }^{23}$.

In previous studies, patients with scores of less than 21 had a mortality rate ranging from $0-2.3 \%$ and those with MPI between 21 and 29 had a mortality rate of approximately $65 \%{ }^{24}$. MPI score of more than 29 had the highest mortality, up to more than $80 \%$ in some studies. These authors believed the accuracy of MPI to be comparable or slightly superior to that of other sepsis scoring systems, including APACHE $\mathrm{II}^{25,26}$.

\section{CONCLUSION}

Categorizing in different groups can help to tailor the treatment for individual patient. Furthermore, scoring patients into different risk groups could help future clinical research by comparing therapeutic interventions in similar patients. MPI is a reliable scoring system for perforation peritonitis. Age is an independent risk factor.

\section{REFERENCES}

1. LeGall J, Loirat P, Alperovitch A, Glacer P, Granthil C, Mathieu D. A simplified acute physiology scores for ICU patients. Crit Care Med. 1984; 12:975-977.

2. Bosscha K, Reijinders $K$, Hulstaert PF, Algra A, Van der Werken C. Prognostic scoring systems to predict outcome in peritonitis and intra-abdominal sepsis. BrJSurg. 1997; 84:1532-34.

3. Adesunkanmi ARK, Ajao OG. The prognostic index in typhoid ulcer perforation. A prospective study of 50 patients. J Roy Coll. Surg Edinb 1997; 42:395-9. 
4. Meakins JL, Solomkin JS, Allo MD, Dellinger EP, Howard RJ, Simmons RL. A proposed classification of intra-abdominal infections. Stratification of etiology and risk for future therapeutic trials. Arch Surg 1984; 119:1372-8.

5. Knaus WA, Draper EA, Wagner DP, Zimmerman JE. APACHE II: a severity of disease classification system. Crit Care Med 1985; 13:818-29.

6. Wacha H, Linder MM, Feldmann U, Wesch G, Gundlach E, Steifensand RA. Mannheims peritonitis index prediction of risk of death from peritonitis. Theoretical Surgery 1987;1:169-177. Dorairajan LN, Gupta S, Deo SVS, Chumber S, Sharma LK. Peritonitis in India- a decade's experience. Trop Gastroenterol. 1995;16:338.

7. Sharma L, Gupta S, Soin AS, Sikora S, Kapoor V. Generalized peritonitis in India- the tropical spectrum. Jpn J Surg. 1991;21:272 7.

8. Washington BC, Villalba MR, Lauter CB, Colville J, Starnes $R$ Cefamandole-erythromycin-heparin peritoneal irrigation. An adjunct to the surgical treatment of diffuse bacterial peritonitis. Surgery. 1983;94:57681

9. Nishida T, Fujita N, Megawa T, Nakahara M, Nakao $K$. Postoperative hyperbilirubinemia after surgery for gastrointestinal perforation. Surg Today. 2002;32:67984.

10. Kologlu M, Elker D, Altun H, Sayek I. Validation of MPI and PIA II in two different groups of patients with secondary peritonitis. Heptogastroenterology 2001;48:147-51.

11. Notash AY, Salimi J, Rahimian H, Fesharaki MS, Abbasi A Evaluation of Mannheim peritonitis index and multiple organ failurescore in patients with peritonitis. Indian J Gastroenterol 2005;24:197-200.

12. Riché F, Panis Y, Laisné MJ, Briard C, Cholley B, BernardPoenaru $O$, et al. High tumor necrosis factor serum level is associated with increased survival in patients with abdominal septic shock: A prospective study in 59 patients. Surgery 1996;120:801-7.

13. Viallon A, Guyomarc'h S, Marjollet O, Berger C, Carricajo A, Robert F, et al. Can emergency physicians identify a high mortality subgroup of patients with sepsis: Role of procalcitonin. European Journal of Emergency Medicine 2008; 15:26-33.
14. McIntyre R, Reinbach D, Cushieri RJ. Emergency abdominal surgery in the elderly. JR Coll Surg Edinb 1997;42:173-8.

15. Rosenthal RA, Andersen DK. Physiologic considerations in the elderly surgical patient. Modern Surgical Care. In: Miller TA, editor. $2^{\text {nd }}$ ed. St Louis, MO: Quality Medical Publishing Inc, 1998.p. 1362-84.

16. Cohen MM. Treatment and mortality of perforated peptic ulcer: A survey of 852 cases. Can Med Assoc J 1971;105:263-9.

17. Seo HJ, Park HK, Park YH, Lee HK, Lee WG, Cho SY, et al. Prognostic factors in duodenal ulcer perforation. J Korean Surg Soc 2001;60:425-31

18. Jhobta RS, Attri AK, Kaushik R, Sharma R, Jhobta A. Spectrum of perforation peritonitis in India-review of 504 consecutive cases. World JEmerg Surg 2006; 1:26.

19. Afridi SP, Malik F, Rahman S, Shamim S, Samo KA. Spectrum of perforation peritonitis in Pakistan: 300 cases Eastern experience. World JEmerg Surg 2008;3:31.

20. Kocer B, Surmeli S, Solak C, Unal B, Bozkurt B, Yildirim O, et al. Mortality and Morbidity - Patients With Peptic Ulcer Perforation. J Gastroenterol Hepatol 2007;22:565-70.

21. Svanes C, Lie RT, Svanes K, Lie SA, Søreide O. Adverse effects of delayed treatment for perforated peptic ulcer. Ann Surg 1994;220:168-75.

22. Billing A, Fröhlich D, Schildberg FW. Prediction of outcome using the Mannheim peritonitis index in 2003 patients. Br J Surg 1994;81:209-13

23. Függer R, Rogy M, Herbst F, Schemper M, Schulz F. Validation study of the Mannheim Peritonitis Index. [Article in German] Chirurg 1988;59:598-601.

24. Ohmann C, Hau T. Prognostic indices in peritonitis. Hepatogastroenterology 1997;44:937-46.

25. Pacelli F, Doglietto GB, Alfieri S, Piccioni E, Sgadari A, Gui D, et al. Prognosis in intra-abdominal infections. Multivariate analysis on 604 patients. Arch Surg 1996;131:641-5. 